\title{
Becoming a Librarian
}

\author{
by Stuart Ferguson, Senior Lecturer, University of \\ Canberra. \\ Stuart Ferguson outlined the many paths a student can \\ take to become a librarian.
}

W

hen Nancy first mentioned the topic Becoming a Librarian I thought it sounded quite straightforward but the more I thought about it, the less straightforward it became. We all think we know what a librarian is but there are at least two complications. First, our concept of what a librarian is and does is changing, as the workplace changes and as people who have become (what we call) librarians enter related fields of employment such as web management and knowledge management. Reasons for becoming a librarian have shifted. Liking books may not be enough and may even be irrelevant. Second, who is a librarian? Is it the person who works in a library or someone recognised by the professional association as a 'professional librarian'? I suspect we all think of the latter but it is worth bearing in mind the large body of paraprofessionals in the workforce, some of whom fill roles that are just as, even more 'professional' than the roles filled by many newly qualified 'librarians'. I also suspect that many of our users think a librarian is simply someone who works in a library.

I am also conscious of the 'NZ' in ANZTLA and of the fact that, although there are strong commonalities between the professional groupings on either side of the Tasman, there are slightly different pathways to becoming a librarian, so I'll try to highlight those differences and not to focus too strongly on over twenty years experience in the 'West Island'.

Now I am going on the assumption that when we're talking about librarians we're talking about 'professional' librarians. We all have our own ideas of what constitutes a professional, but perhaps it's worth considering some of the key attributes. In his History of Library Education (1969), Gerald Bramley lists four:

1. The existence of a body of theoretical knowledge serving as the foundation for professional practice

2. The need for extensive education and training

3. The existence of a formal professional association

4. The development of specific standards of professional competency deemed appropriate for entry into the profession (Bramley 1969, p. 7; cited in Hallam, 2007)

Many would regard the first of these as critical. Without a body of knowledge to inform practice - whether medical, legal or financial - there could be no profession. One of the issues facing Librarianship is the fact that librarians increasingly need a sound understanding across a range of information, communication and computing sciences. Nonetheless, there are important continuities in the body of knowledge underlying the practice of Librarianship, such as the principles of information organisation and description, which apply just as much to taxonomies and metadata as they do to classification and cataloguing. 
"While the

early days of

librarianship are

characterised by

an apprenticeship

model, we have

moved to a model

in which formal

education is

considered the

essential first

step on the road

to becoming a

librarian."
One of the points on which most of us agree is the need for extensive education and training. While the early days of librarianship are characterised by an apprenticeship model, we have moved to a model in which formal education is considered the essential first step on the road to becoming a librarian. Now it's worth pointing out that this was not always the case. Prior to the introduction of formal university courses (notably, University of New South Wales' Graduate Diploma of Librarianship in 1960), leading institutions, such as the then Public Library of New South Wales, ran library training programs (Hallam, 2007, p. 314). This survives to a limited degree, with the National Library of Australia, for instance, often employing people with non-LIS qualifications and providing training and short courses in relevant areas of information and library work - in effect, growing its own librarians.

In Australia, there is a range of educational pathways to becoming a professional librarian. Indeed, one of the issues raised by some employers and educators is that there are too many pathways and that it is often difficult to make meaningful comparisons between different educational programs - both for the employers and for prospective students.

I'll return to this issue later and note for now the current pathways in Australia. There are basically three:

- Undergraduate Library and Information Science degree

- Graduate Diploma in Library and Information Science

- Master of Library and Information Science.

Bachelors degrees, graduate diplomas and Masters in LIS are all currently recognised by ALIA for professional membership. From a quick check of the ALIA website, there are currently six undergraduate programs recognised by ALIA, seven graduate diploma courses recognised by ALIA or undergoing recognition processes and nine Masters programs recognised by ALIA or undergoing recognition processes, including Teacher Librarianship courses. It's worth noting that the Graduate Diploma is no longer a common qualification outside Australia; the only other one in the English-speaking world being the South African one (Hallam \& Calvert, 2009, p. 294).

Another pathway worth mentioning is the Library Technicians' programs offered by colleges of Technical and Further Education (TAFE). These courses are designed as a pathway to a distinct qualification and a different type of ALIA membership from the professional one, so it is interesting to note the fact that some people use them as a pre-professional award. A significant percentage of students enrolled in undergraduate programs already have TAFE qualifications (figures not provided) and indeed receive significant credit for their TAFE studies from all Australian universities. More surprisingly, there are cases in which people with non-LIS degrees undertake TAFE LIS courses, even of graduates who complete a TAFE qualification first then apply to universities for postgraduate 


\section{"It is worth}

acknowledging that

courses recognised

by our professional

\section{associations do}

not consist only

of theoretical

study but are

required to include

some exposure

to professional

practice"
LIS programs.

It would be worth highlighting the fact that the different pathways available to LIS students in New Zealand are less complex than in Australia. This is partly a matter of population size and a matter of history and the fact that New Zealand did not have the same proliferation of institutions teaching LIS as Australia. In New Zealand, there are essentially two institutions teaching general LIS programs: a university that offers postgraduate programs and a polytechnic offering undergraduate and non-graduate programs (Hallam \& Calvert, 2009, p. 299).

It is worth acknowledging that courses recognised by our professional associations do not consist only of theoretical study but are required to include some exposure to professional practice, whether this is the traditional work placement of a specified number of weeks duration or something more task orientated, such as an information management project. ALIA's course recognition documentation (about which Jane can tell you much more) allows for a range of professional activities and, indeed, a survey last year suggested that different universities have widely ranging requirements, in terms of activities, assessment and duration of professional practice.

One of the issues to come up periodically is the need for mentorship, both in the case of LIS students and that of new graduates - a point that we may want to discuss later. Here it is worth noting that, although we have gone from an apprenticeship model to one that relies heavily on formal, tertiary education, the mentoring role remains an important one - a belief fostered by both Australian and New Zealand professional associations and indeed, some tertiary institutions; not least my own, which over the years has sought partnerships with industry in an attempt to develop strong mentorship programs.

Issues of mentorship and professional development of course are part of being a librarian and therefore fall within Jane's part of the discussion, but exposure to professional practice is also part of academic programs and the immediate post-qualification period therefore part of the process of becoming a librarian. It has become commonplace to point out that the first professional qualification is only the start of becoming a professional librarian, not the end. This has been recognised and promoted for many years in the UK, where the professional association, the Chartered Institute of Library and Information Professionals (CILIP), has a category of membership called 'Chartered Membership' - a second level of professional qualification and described by the Institute as the 'gold standard' for information and library professionals. Chartered Membership is not an academic qualification but is seen by the Institute as 'recognition of the highest standards of professional practice and a commitment to undertake continuing professional development' (2007, p. 4).

Here it is worth noting LIANZA's registration requirements, which underline the value the Association attaches to professional 
"one of the

important factors

in becoming a

librarian is the

existence of a

professional

association,

which, apart from

anything else, acts

as a standards

body; defining,

in consultation

with employers,

educators and

other professional

members, the

body of knowledge

and core skills

and attributes

required by would-

be librarians to

be recognised as

professionals" practice in becoming a librarian. Those who graduate after the 1 st of July 2007 can become registered LIANZA members but first have to complete a mentoring program. This involves registrants finding a mentor, preparing a Professional Training Plan, implementing the Plan and maintaining a Portfolio of Learning throughout the mentorship period (12 months). At the end of the period of supervised initial professional training, The Registration Board looks for evidence that the registrant meets a range of criteria, including having at least an introductory level awareness of practice across most elements of the Association's Body of Knowledge, having applied a breadth of practice relevant to the registrant's role, understanding the ethical base of the profession and the code of professional conduct, participating in professional networks and activities, and understanding the New Zealand context of their work (Library \& Information Association New Zealand Aotearoa, 2008a).

Now the preceding discussion underlines the fact that one of the important factors in becoming a librarian is the existence of a professional association, which, apart from anything else, acts as a standards body; defining, in consultation with employers, educators and other professional members, the body of knowledge and core skills and attributes required by would-be librarians to be recognised as professionals. On a historical note, professional bodies have not always assumed this role. Some people here may recall the fact that ALIA (or its earlier manifestations, the LAA and, before that, the Australian Institute of Librarians) was effectively an examining body, which from 1944 until 1980 ran a qualifying examination, later renamed the registration examination. These days ALIA provides a statement of core knowledge, skills and generic attributes, against which academic institutions seeking recognition must be able to map their courses; course recognition criteria and processes; and a system of annual course returns, which require institutions with recognised programs to report on a range of specified issues, including course developments.

Currently the core fields of knowledge listed by ALIA include:

- knowledge of the broad context of the information environment;

- information seeking;

- information infrastructure, which includes resource management;

- information organisation;

- information access;

- information services, sources and products;

- information literacy education; and

- generation of knowledge, which includes commitment to a culture of research and evidence-based information practice.

LIANZA has a standard, called the Body of Knowledge, which is largely similar to the ALIA statement. It is a well-articulated document and is based on the IFLA Guidelines, with the addition 
"Those seeking to become librarians are also required to possess a set of generic skills and attributes" of 'Awareness of indigenous knowledge paradigms, which in the New Zealand context refers to Māori' (Library \& Information Association New Zealand Aotearoa, 2008b).

What is represented in these statements of knowledge could be described as that which differentiates LIS from other fields of professional knowledge, such as records management, although clearly there are strong areas of overlap, such as information organisation and description.

Those seeking to become librarians are also required to possess a set of generic skills and attributes; currently seen by ALIA to include:

- effective communication skills;

- professional ethical standards and social responsibility;

- project management skills;

- critical, reflective, and creative thinking;

- problem-solving skills;

- business acumen;

- ability to build partnerships and alliances;

- effective team relationship skills;

- self management skills;

- a commitment to life-long learning;

- relevant information and communications technology and

ICT application skills; and

- appropriate information literacy skills.

That concludes a quick gallop through the current pathways to becoming a librarian - and I apologise if it was a gallop and if it's a case of preaching to the converted and already well informed (I'm not even sure if I'm qualified to preach to a gathering of theological librarians). In the remaining two minutes I'd like to summarise some of the issues currently facing the various stakeholders in the education and training of librarians, namely, employers, educators, prospective students and the professional bodies (including their members). First there is the perennial issue of education versus training. We all (employers included) want our new librarians to have a sound theoretical knowledge of the field, something that should produce the flexible, adaptable and creative librarians that we want, but there is also demand for practical skills. How many times have we heard the comment "Why do LIS graduates arrive here unable to catalogue?" or "What kind of information searching skills do they teach at library school?" (I'm not going to address this issue - although I'm happy to - I simply raise it as a possible discussion point.)

Second, there is the point raised already about the multiplicity of awards in Australia, which can be confusing to both employers and prospective students. Linked to that is the phenomenon of credential creep. There is a suggestion that the Graduate Diploma should be phased out in favour of the Masters degree. Some have pointed to the difficulty of obtaining government-funded places for Masters students, although this has not been a problem for my 
"how are

\section{specialisations}

such as theological

librarianship, law

librarianship or

health information

catered for? There

is a tendency for

institutions to offer

similar rafts of

subjects, which is

undesirable, given

the diverse nature

of library work." current institution.

Periodically there are also calls for the pathway to becoming a librarian to be limited to postgraduate study. Given the large numbers of baby-boomers predicted to leave the workforce in the next few years, some might argue that now is not the time to be limiting the pathways to becoming a professional librarian. (Interestingly, this is not a new issue because in Australia postgraduate-only entry to the profession was proposed back in the early 1960s.) Another one of the perennial issues in our profession is the perceived gap between what employers need and what educators provide. It has been suggested recently by a leading member of our profession that this gap has been widening and there have been many conversations about workforce planning and curriculum change. If you check the ALIA website for LIS courses you will notice that several institutions have requested course recognition.

There are also curriculum issues relating to teaching in a multidisciplinary field and to the increasing diversity of employment opportunities for those with LIS qualifications: for instance, in areas of the Knowledge Management domain. Should areas such as KM become part of the core curriculum or are they better handled as elective specialisations?

Some have also raised the issue of the position of LIS departments in their universities. These are situated in a wide range of schools and faculties: arts, education, business, management and IT, for instance. Some see this as a regrettable lack of coherence but I tend to see this as a positive since it means that our programs tend to have distinct emphases and areas of specialisation, which should serve a diverse profession like ours well.Finally, there is a multiplicity of programs in Australia, with a much higher percentage of institutions teaching LIS than in any other English-speaking country. Students need diversity in terms of intellectual leadership, which is not easy when departments are small - although this can be overcome to some extent through the involvement of professionals: for instance, through the use of Web technologies. More seriously, how are specialisations such as theological librarianship, law librarianship or health information catered for? There is a tendency for institutions to offer similar rafts of subjects, which is undesirable, given the diverse nature of library work. Some have called for universities to collaborate on course and subject delivery but, given competition in a relatively small market, this is unlikely to happen.

Potential discussion points for later:

- Education versus training

- Multiplicity of awards in Australia

- Credential creep

- Postgraduate versus undergraduate study

- Gap between employers and educators

- Multidisciplinary nature of LIS

- Diversity of employment opportunities 
- Position of 'LIS schools' in institutions

- Size of LIS departments

- Need for range of specialisations.

\section{References}

Bramley, G. (1969). A history of library education. London: Clive Bingley.

Chartered Institute of Library and Information Professionals (2007). Chartership handbook. http://www.cilip.org.uk/NR/ rdonlyres/1C95721A-E2ED-47F6-A8F5- BDFA131A3B25/0/ Chartershiphandbook.pdf

Hallam, G. (2007). 'Education for library and information service'. In S.Ferguson (Ed.) Libraries in the twenty-first century: Charting new directions in information services. Wagga Wagga, NSW: Centre for Information Studies.

Hallam, G. \& Calvert, P. (2009). 'LIS education. In I. Abdullahi (Ed.) Global library and information science. München: K.G. Saur.

Library \& Information Association New Zealand Aotearoa (2008a). Guidelines for new graduates. http://www.lianza.org.nz/ registration/files/Guidelines_for_New_Graduates.pdf

Library \& Information Association New Zealand Aotearoa (2008b). The library and information sector: Core knowledge, skills and qualities. http://www.lianza.org.nz/registration/files/Body_of_ professional_knowledge.pdf

Dr Stuart Ferguson UC, Senior Lecturer in Information Studies)

He has been an academicsince 1990, when he began leading development of an Information Management specialisation within Charles Sturt University's Librarianship programs. Before that he was a librarian for more than twelve years in Scotland, South Africa and Queensland. He has published in the areas of information technology in libraries, knowledge management, information ethics, librarianship, information organisation and Marxist aesthetics (the subject of his doctorate). Are librarians the ultimate knowledge managers? Published 2008. 